\title{
USIA LAYANAN IPAL SEMANGGI KOTA SURAKARTA BERDASAR PENGGUNAAN AIR DAN VOLUME LIMBAH CAIR RUMAH TANGGA
}

\author{
Siti Qomariyah ${ }^{1}$, Adi Yusuf Muttaqin ${ }^{1}$, dan Budi Utomo ${ }^{1}$

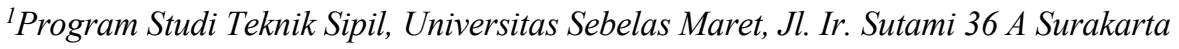 \\ Email: siti.qomariyah@ft.uns.ac.id
}

\begin{abstract}
ABSTRAK
Sanitasi merupakan problem kota-kota besar terkait dengan limbah cair domestik. Di Kota Surakarta, Instalasi Pengolahan Air Limbah (IPAL) Semanggi merupakan sistim pengolahan limbah cair secara terpusat yang melayani kawasan selatan kota dari 28 kalurahan dengan jumlah pelanggan 9.323 sambungan rumah. Penelitian ini mengkaji usia layanan IPAL Semanggi berdasar penggunaan air dan volume limbah cair. Metode penelitian adalah metode deskriptif. Hasil penelitian ini menunjukkan bahwa pada tahun 2017, IPAL Semanggi dengan kapasitas 60 liter/detik hanya mampu melayani $17 \%$ - 26\% limbah cair dari penduduk di area layanan. Berdasar proyeksi pelanggan, untuk kebutuhan air 170, 160, dan 150 liter/orang/hari, IPAL Semanggi hanya mampu mengolah limbah cair berturut-turut hingga tahun 2020, 2022, dan 2024.
\end{abstract}

\begin{abstract}
Sanitation is a problem of big cities related to its domestic waste water. In the city of Surakarta, the wastewater treatment plant of Semanggi is a centralized wastewater treatment system covering the south area of the city that consists of 28 villages with 9323 customers of home connections. This study examined the useful life of the services of the Semanggi plants based on the volume of water use and waste water. The study applied a descriptive method and resulted in only $17 \%$ - 26\% of domestic wastewater in the service areas that could be treated by the plant having capacity of 60 liter/second in the year of 2017. Based on the projection of customers, for water use by 170, 160, and 150 liter/person/day, the waste water treatment plant of Semanggi will only treat the waste water by the year of 2020, 2022, and 2024 respectively.
\end{abstract}

\section{PENDAHULUAN}

Limbah cair domestik menjadi problem di banyak kota besar terutama kota besar dengan jumlah penduduk dan tingkat kepadatan yang tinggi. Di Indonesia, sistim pengolahan limbah cair dengan Instalasi Pengolahan Air Limbah (IPAL) telah dibangun di 12 kota (Surakarta, Medan, Prapat, Jakarta, Bandung, Cirebon, Yogyakatya, Banjarmasin, Bali, Balikpapan, Tangerang, dan Batam), namun semua sistim tersebut baru dapat melayani $10 \%$ dari jumlah penduduk Indonesia (Hendrawan, et al., 2013).

IPAL-IPAL tersebut merupakan sistim pengolahan limbah cair secara terpusat (on site) yang merupakan upaya untuk menunjang sanitasi kota dengan tujuan untuk memperbaiki atau mengurangi polusi air limbah sehingga dapat menunjang kesehatan masyarakat umum dan kualitas lingkungan masyarakat kota (TWB, 2013).

Kota Surakarta dengan luas 44,4 km2 berpenduduk 514.171 jiwa dengan tingkat kepadatan 11.675 orang per km² (BPS, 2017). Sistem pengelolaan limbah domestik di kota ini mencakup sistim off site sebesar 18\% (sewage system dengan perpipaan IPAL) dan sisanya berupa sistim on site yang terdiri dari fasilitas mandi cuci kakus (MCK), tanki septik, dan IPAL komunal. Kota Surakarta telah memiliki tiga buah IPAL yaitu IPAL Semanggi dengan kapasitas 60 liter/detik yang melayani 8.998 SR (sambungan rumah) di wilayah selatan, IPAL Mojosongo dengan kapasitas 50 liter/detik melayani 5.426 SR di wilayah utara, dan IPAL Pucangsawit dengan kapasitas 40 liter/detik 577 SR di wilayah tengah (PDAM Kota Surakarta, 2016). Pada tahun 2017, pelanggan SR di IPAL Semanggi bertambah menjadi 9.323 SR (PDAM Kota Surakarta, 2017)

Jika jumlah penduduk dan jumlah pelanggan SR semakin bertambah, penambahan kapasitas layanan IPAL diperlukan. Tulisan ini mengkaji usia layanan IPAL Semanggi berdasar volume pemakaian air rumah tangga (domestik) penduduk kota dan persentase produksi limbah cair yang dihasilkan. 


\section{TINJAUAN PUSTAKA}

Sistim pengolahan limbah cair terpusat adalah sistim pengolahan yang menggunakan jaringan sistim perpipaan untuk mengumpulkan dan mengolah limbah cair hingga menghasilkan air yang telah berkurang kadar polutannya. Keuntungan dari sistim pengolahan terpusat antara lain mempunyai usia efektif yang lebih lama, dapat mengakomodasi semua jenis limbah cair, cocok untuk kawasan berpenduduk padat, polusi terhadap air tanah dan badan air dapat dihindari. Kelemahan dari sistim ini antara lain biaya investasi, biaya operasional, dan biaya pemeliharaan sangat tinggi, tidak dapat dilakukan secara individu, membutuhkan teknologi tinggi, manfaat diperoleh setelah beroperasi dalam jangka panjang, membutuhkan waktu yang cukup panjang dalam perencanaan dan pelaksanan, dan membutuhkan menejemen operasional serta pemeliharaan yang memadai (Prihandini et al., 2011). Biaya investasi yang besar untuk pembuatan IPAL karena kebutuhan pengadaan lahan yang luas, pembangunan kolam aerasi, kolam pengolah lumpur, kolam rotasi-biologi, dan pengadaan mesin-mesin mekanik. Dengan demikian, sistim terpusat atau konvensional tersebut sangat mahal bagi negara berkembang (Hendrawan, et al., 2013).

Sistim IPAL Semanggi terdiri atas bangunan-bangunan: 1. Saringan untuk menyaring material padat yang ada di dalam limbah cair; 2. Kolam tandon (Great Chamber) untuk menampung limbah cair setelah disaring dan memisahkan lumpur dan cairan; 3. Bak Ekualisasi untuk meratakan fluktuasi aliran masuk; 4. Bak Aerasi sebagai tempat berlangsunggnya proses fisika, kimia, dan biologi; 5. Bak Sedimentasi untuk mengendapkan semua material sedimen dalam limbah cair; 6. Bak Pengering Lumpur sebagai fasilitas untuk mengeringkan lumpur. Pengelolaan air limbah di Kota Surakarta direncanakan terdiri dari 30\% sistim perpipaan atau off site dan 70\% dengan sistim on site yang terdiri dari septik tank, IPAL komunal, dan sistim mandi-cuci-kakus (MCK) (PDAM Surakarta, 2016).

Kebutuhan air baku perkotaan untuk kota dengan penduduk 500.000-1.000.000 jiwa dan 100.000-500.000 jiwa berturut-turut adalah 170 liter/org/hari dan 150 liter/org/hari (Ditjen. Cipta Karya - DepKimPrasWil, 2002). Limbah cair domestik yang dihasilkan oleh setiap orang adalah 60-80\% dari kebutuhan air (Morel \& Diener, 2006; Barbara \& Joelle, 2005),

Proyeksi jumlah penduduk dan jumlah sambungan rumah (SR) pelanggan IPAL dianalisis berdasar Metode Aritmatik dan Metode Geometrik berikut.

Metode Aritmatik:

$$
\begin{aligned}
& \mathrm{P}_{\mathrm{n}}=\mathrm{P}_{\mathrm{o}}+\mathrm{k}\left(\mathrm{T}_{\mathrm{n}}-\mathrm{T}_{\mathrm{o}}\right) \\
& \text { Dengan: } \\
& \mathrm{P}_{\mathrm{n}} \quad=\text { Jumlah penduduk pada tahun ke- } \mathrm{n} \\
& \mathrm{P}_{\mathrm{o}} \quad=\text { Jumlah penduduk pada tahun awal proyeksi } \\
& \mathrm{k} \quad=\text { Konstanta aritmatik } \\
& \mathrm{T}_{\mathrm{n}} \quad=\text { Tahun ke-n } \\
& \mathrm{T}_{\mathrm{o}} \quad=\text { Tahun awal proyeksi }
\end{aligned}
$$

MetodeGeometrik:

$$
\begin{aligned}
& \mathrm{P}_{\mathrm{n}}=\mathrm{P}_{\mathrm{o}} \times(1+\mathrm{r})^{\mathrm{n}} \\
& \text { Dengan: } \\
& \text { Pn = Jumlah penduduk pada tahun ke n } \\
& \text { Po = Jumlah penduduk pada tahun awal proyeksi } \\
& \mathrm{r} \quad=\text { Laju pertumbuhan penduduk } \\
& \mathrm{n} \quad=\text { Interval tahun }
\end{aligned}
$$

\section{METODE PENELITIAN}

Kajian ini merupakan penelitian deskriptif dengan obyek studi adalah IPAL Semanggi yang melayani pengolahan limbah cair dari 28 Kalurahan di wilayah selatan Kota Surakarta. Tahap-tahap penelitian meliputi:

a. Pengumpulan data sekunder berupa data pelanggan yang dilaksanakan dalam bulan Maret-April 2018. Data pelanggan pengolahan limbah cair dalam satuan sambungan rumah (SR) diperoleh dari PDAM Kota Surakarta. 
b. Pengumpulan data penduduk yang diperoleh dari Dinas Kependudukan dan Catatan Sipil Pemerintah Kota Surakarta dan Badan Pusat Statistik Kota Surakarta.

c. Analisis data pelanggan dan data penduduk menggunakan Metode Aritmatik dan Metode Geometrik untuk mendapatkan proyeksi penduduk dan proyeksi pelanggan SR untuk beberapa tahun ke depan.

d. Tinjauan ke IPAL Semanggi guna mengetahui kondisi eksisting IPAL dan mendapatkan informasi terkait kapasitas / operasional pengolahan limbah dari staf setempat.

e. Pembahasan hasil analisis untuk mendapatkan kesimpulan.

\section{HASIL DAN PEMBAHASAN}

Proyeksi jumlah penduduk di wilayah selatan yang dilayani oleh IPAL Semanggi yang diestimasi berdasar Metode Aritmatik dan Metode Geometrik dapat dilihat pada Tabel 1.. Proyeksi penduduk tahun 2018 - 2025 berdasar data penduduk tahun 2014 dan 2017. Proyeksi sambungan rumah (SR) tahun 2018 - 2025 berdasar data SR tahun 2012 sampai dengan 2017.

Tabel 1. Proyeksi jumlah penduduk dan jumlah sambungan rumah (SR) di area layanan IPAL Semangi.

\begin{tabular}{ccccr}
\hline \multirow{2}{*}{ Tahun } & $\begin{array}{c}\text { Jumlah Penduduk } \\
\text { Aritmatik }\end{array}$ & Geometri & $\begin{array}{c}\text { Sambungan Rumah } \\
\text { Aritmatik }\end{array}$ & Geometri \\
\hline 2017 & 223,376 & 223,376 & 9,323 & 9,323 \\
2018 & 224,442 & 224,452 & 9,562 & 9,584 \\
2019 & 225,508 & 225,534 & 9,802 & 9,853 \\
2020 & 226,574 & 226,620 & 10,041 & 10,130 \\
2021 & 227,640 & 227,712 & 10,281 & 10,414 \\
2022 & 228,706 & 228,809 & 10,520 & 10,706 \\
2023 & 229,772 & 229,912 & 10,759 & 11,006 \\
2024 & 230,838 & 231,020 & 10,999 & 11,315 \\
2025 & 231,904 & 232,133 & 11,238 & 11,632 \\
\hline
\end{tabular}

Tabel 1 di atas menunjukkan bahwa Metode Aritmatik dan Metode Geometrik memberikan hasil estimasi jumlah penduduk dan jumlah sambungan rumah hingga tahun 2025 yang hampir sama. Proyeksi kebutuhan air dan jumlah limbah cair selanjutnya menggunakan Metode Geometrik.

\section{Layanan IPAL Semanggi berdasar jumlah penduduk tahun 2017}

Pada tahun 2017, jumlah penduduk di kawasan selatan (area layanan IPAL Semanggi) adalah 223.376 orang (PDAM, 2018). Kebutuhan air untuk 223.376 orang dan limbah cair yang dihasilkan disajikan pada Tabel 2.

Tabel 2. Kebutuhan air dan limbah cair berdasarkan jumlah penduduk pada tahun 2017

\begin{tabular}{cccccccccc}
$\begin{array}{l}\text { Kebutuhan air } \\
\text { (liter/orng/hari) }\end{array}$ & $\begin{array}{l}\text { Kebutuhan air } \\
223.376 \text { orang } \\
\text { (liter/hari) }\end{array}$ & $\begin{array}{l}\text { Kebutuhan air } \\
\text { (liter/detik) }\end{array}$ & \multicolumn{3}{c}{$\begin{array}{c}\text { Limbahcair } \\
\text { (liter/detik) }\end{array}$} & \multicolumn{3}{c}{$\begin{array}{l}\text { Prosentase (\%) } \\
\text { layanan IPAL }\end{array}$} \\
\hline & & Q & $60 \%$ & $70 \%$ & $80 \%$ & $60 \%$ & $70 \%$ & $80 \%$ \\
\hline$(1)$ & $(2)$ & $(3)$ & $(4)$ & $(5)$ & $(6)$ & $(7)$ & $(8)$ & $(9)$ \\
\hline 170 & $37,973,920$ & 440 & 264 & 308 & 352 & 0.23 & 0.20 & 0.17 \\
160 & $35,740,160$ & 414 & 248 & 290 & 331 & 0.24 & 0.21 & 0.18 \\
150 & $33,506,400$ & 388 & 233 & 271 & 310 & 0.26 & 0.22 & 0.19 \\
100 & $22,337,600$ & 259 & 155 & 181 & 207 & 0.39 & 0.33 & 0.29 \\
90 & $20,103,840$ & 233 & 140 & 163 & 186 & 0.43 & 0.37 & 0.32 \\
80 & $17,870,080$ & 207 & 124 & 145 & 165 & 0.48 & 0.41 & 0.36 \\
70 & $15,636,320$ & 181 & 109 & 127 & 145 & 0.55 & 0.47 & 0.41 \\
60 & $13,402,560$ & 155 & 93 & 109 & 124 & 0.64 & 0.55 & 0.48 \\
\hline
\end{tabular}

Kapasitas IPAL Semanggi adalah 60 liter/detik (PDAM, 2018). Tabel di atas (kolom 4, 5, 6) menunjukkan bahwa pada tahun 2017 jumlah limbah cair yang dihasilkan oleh 223.376 orang yang tinggal di area layanan IPAL 
Semanggi tidak dapat dilayani oleh IPAL Semanggi, meskipun dengan asumsi penggunaan air terendah (60 liter/orang/hari) dan estimasi produksi limbah cair terendah (60\% dari kebutuhan air). Besaran terendah limbah cair 93 liter/detik, jauh lebih besar dari kapasitas IPAL Semanggi (60 liter/detik).

Kolom 7, 8, dan 9 pada tabel di atas menunjukkan prosentase layanan IPAL Semanggi dengan kapasitas 60 liter/detik hanya mampu mengolah limbah cair penduduk pada besaran $23 \%-64 \%$ untuk besaran limbah $60 \%$ dari kebutuhan air; 20\% - 55\% untuk besaran limbah 70\% dari dari kebutuhan air; dan 17\% - 48\% untuk besaran limbah $80 \%$ dari dari kebutuhan air.

Berdasar Ditjen. Cipta Karya - DepKimPrasWil (2002), kota besar dengan penduduk antara 500.000 jiwa 1.000.000 jiwa seperti Kota Surakarta membutuhkan air sebesar 150 - 170 liter/orang/hari, maka IPAL Semanggi pada tahun 2017 hanya mampu melayani antara 17\% - 26\%. Jika layanan IPAL Semanggi dikehendaki sebesar 30\% (PDAM Surakarta, 2016), kapasitas IPAL harus dinaikkan.

\section{Layanan IPAL Semanggi berdasar jumlah proyeksi pertumbuhan sambungan rumah (SR)}

Berdasarkan Kriteria Perencanaan Ditjen Cipta Karya Dinas PU tahun 1996, satu sambungan rumah (SR) terdiri atas 5 orang, dan kebutuhan air berdasar jumlah penduduk di kota besar adalah 170 liter/orang/hari, dan di kota sedang adalah 150 liter/orang/hari. Jumlah limbah cair yang dihasilkan berdasar SR dengan kebutuhan air 170 liter/hari, 160 liter/orang/hari, dan 150 liter/orang/hari, dan estimasi limbah cair sebesar 60\%, 70\%, dan 80\% dari kebutuhan air disajikan pada Tabel 3.

Tabel 3. Kebutuhan air dan limbah cair berdasarkan jumlah sambungan rumah (SR)

\begin{tabular}{|c|c|c|c|c|c|c|c|c|c|c|c|}
\hline \multirow[t]{2}{*}{ Tahun } & \multirow[t]{2}{*}{$\mathrm{SR}$} & \multirow[t]{2}{*}{ Orang } & \multicolumn{3}{|c|}{$\begin{array}{l}\text { Limbah cair (lt/detik) } \\
\text { dari } 170 \text { 1/orang/hari }\end{array}$} & \multicolumn{3}{|c|}{$\begin{array}{l}\text { Limbah cair (lt/detik) } \\
\text { dari } 160 \text { l/orang/hari }\end{array}$} & \multicolumn{3}{|c|}{$\begin{array}{l}\text { Limbah cair (lt/detik) } \\
\text { dari } 150 \text { 1/orang/hari }\end{array}$} \\
\hline & & & $60 \%$ & $70 \%$ & $80 \%$ & $60 \%$ & $70 \%$ & $80 \%$ & $60 \%$ & $70 \%$ & $80 \%$ \\
\hline 2017 & 9,323 & 46,615 & 55 & 64 & 73 & 52 & 60 & 69 & 49 & 57 & 65 \\
\hline 2018 & 9,584 & 47,922 & 57 & 66 & 75 & 53 & 62 & 71 & 50 & 58 & 67 \\
\hline 2019 & 9,853 & 49,266 & 58 & 68 & 78 & 55 & 64 & 73 & 51 & 60 & 68 \\
\hline 2020 & 10,130 & 50,648 & 60 & 70 & 80 & 56 & 66 & 75 & 53 & 62 & 70 \\
\hline 2021 & 10,414 & 52,068 & 61 & 72 & 82 & 58 & 67 & 77 & 54 & 63 & 72 \\
\hline 2022 & 10,706 & 53,528 & 63 & 74 & 84 & 59 & 69 & 79 & 56 & 65 & 74 \\
\hline 2023 & 11,006 & 55,030 & 65 & 76 & 87 & 61 & 71 & 82 & 57 & 67 & 76 \\
\hline 2024 & 11,315 & 56,573 & 67 & 78 & 89 & 63 & 73 & 84 & 59 & 69 & 79 \\
\hline 2025 & 11,632 & 58,159 & 69 & 80 & 92 & 65 & 75 & 86 & 61 & 71 & 81 \\
\hline
\end{tabular}

Tabel 3 di atas menunjukkan bahwa berdasar jumlah SR, IPAL Semanggi hanya mampu mengolah limbah cair hingga tahun 2020 jika kebutuhan air 170 liter/orang/hari dan prosentase limbah $60 \%$ dari kebutuhan air. IPAL Semanggi mampu mengolah limbah cair hingga tahun 2022 jika kebutuhan air 160 liter/orang/hari dan prosentase limbah 60\% dari kebutuhan air, namun hanya mampu pada tahun 2017 saja jika persentase limbah cair $70 \%$ dari kebutuhan air. Jika kebutuhan air 150 liter/orang/hari, IPAL Semanggi mampu mengolah limbah cair hingga tahun 2024 dengan prosentase limbah 60\% dari kebutuhan air dan tahun 2019 dengan prosentase limbah $70 \%$ dari kebutuhan air. Dengan demikian semakin besar jumlah pemakaian air, semakin pendek usia kemampuan pengolahan limbah, dan semakin besar persentase limbah cair, semakin pendek usia kemampuan pengolahan limbah. Untuk besaran limbah cair 80\% dari kebutuhan air, menghasilkan debit yang lebih besar dari kapasitas IPAL Semanggi sehingga tidak semua limbah cair mampu diolah.

\section{KESIMPULAN}

IPAL Semanggi yang merupakan sistim terpusat pengolahan limbah cair di Kota Surakarta tidak cukup untuk menanggulagi sanitasi kota dengan mengolah limbah cair dari seluruh penduduk di area layanannya. Kebutuhan air penduduk Kota Surakarta antara 150 - 170 liter/orang/hari, maka berdasar jumlah penduduk tahun 2017 di area layanan kawasan selatan (28 Kalurahan), IPAL Semanggi dengan kapasitas 60 liter/detik hanya mampu melayani melayani 17\% - 26\% dari limbah cair semua penduduk. Jika laju pertumbuhan penduduk bertambah pada tahun 2018 dan tahun-tahun berikutnya, persentase layanan IPAL Semanggi akan semakin mengecil. 
Berdasar proyeksi sambungan rumah (SR), dengan kebutuhan air 170 liter/orang/hari, 160 liter/orang/hari, dan 150 liter/orang/hari, IPAL Semanggi hanya mampu mengolah limbah cair berturut-turut hingga tahun 2020, 2022 , dan 2024 (dengan persentase limbah 60\% dari kebutuhan air). JIka presentase limbah cair 70\% atau 80\% dari pemakaina air, usia layanan dengan 60 liter/detik akan lebih pendek. Semakin besar jumlah pemakaian air, semakin pendek usia layanan IPAL Semanggi, dan semakin besar persentase limbah cair, semakin pendek juga usia layanan IPAL tersebut..

Pengolahan limbah cair perkotaan guna mendukung sanitasi kota dapat dibantu dengan sistim desentralisasi lain melalui sistim pengolahan komunal dari beberapa rumah atau sistim mandiri di masing-masing rumah tinggal.

\section{DAFTAR PUSTAKA}

BPS-Badan Pusat Statistik Kota Surakarta. 2017. Kota Surakarta Dalam Angka. Katalog: 1102001.3372. ISSN: 0215-6164. NO. Publikasi: 33726-1601.

Barbara I. dan Joelle M. 2005. Greywater treatment on household level in developing countries - a state of the art review. Federal Institute of Technology Zurich, Swiss.

Ditjen Cipta Karya Departemen PU. 1996. Kriteria Perencanaan Air Bersih.

Dispendukcapil-Dinas Kependudukan dan Catatan Sipil Pemerintah Kota Surakarta. 2018. Data Jumlah Penduduk di 28 Kalurahan wilayah Selatan Kota Surakarta.

Hendrawan, H., Widarnako, S., Setyo S M and Robertus WT. 2013. Evaluation of Centralized WWTP and The Need of Communal WWTP in Supporting Community-Based Sanitation in Indonesia. European Scientific Journal. 917 230-231

Morel, A., Diener, S. 2006. Greywater Management in Low and Middle Income Countries: Review of different treatment systems for households and neighbourhoods. Sandec Report No 14/6. Swiss Federal Institute of Aquatic Science and Technology. Dubendorf. Switzerland.

PDAM Kota Surakarta. 2016. Pengelolaan Air Limbah Kota Surakarta. $4^{\text {th }}$ International Workshop on Domestic Wastewater Treatment in Asia. Jakarta. 27-28 September

PDAM Kota Surakarta. 2017. Data Pelanggan Sambungan Rumah (SR) IPAL Semanggi.

Prihandini, M. dan Firdayati, M. 2011. Current Situation and Consideration Wastewater Treatment Systems for Big Cities in Indonesia (Case Study: Surabaya and Bandung). Journal of Water Sustainability, Vol. 1. Issue 2: $97-104$.

TWB-The World Bank. 2013. East Asia Pacific Region Urban Sanitatin Review: Indonesia Country Study. Australian Aid. 